\title{
Recent Developments in the Partial Oxidation of Methane to Syngas
}

\author{
Saleh A. Al-Sayari, ${ }^{*}, 12$ \\ ${ }^{1}$ Advanced Materials and NanoResearch Center, Najran University, P.O. Box: 1988, Najran 11001, Saudi Arabia \\ ${ }^{2}$ Chemistry Department, Faculty of Science and Art at Sharurah, Najran University, Saudi Arabia
}

\begin{abstract}
Natural gas is catalytically converted into several bulk chemicals such as ammonia, methanol, dimethyl ether, and synthetic liquid fuels by Fischer-Tropsch synthesis and similar processes. The main step in the conversion of natural gas to these products is the production of synthesis gas with the desired composition ranging from $\mathrm{H}_{2} / \mathrm{CO}=3: 1$ used for the production of ammonia to the 1:1 mixture preferred for production of dimethyl ether. Catalysts and catalytic processes are important in the production of synthesis gas from natural gas. In this work, relevant catalytic systems employed recently in the production of syngas by the catalytic partial oxidation of methane, as well as experimental evidences on the reaction mechanisms are examined. Differences in methane dissociation, binding site preferences, stability of OH surface species, surface residence times of active species and contributions from lattice oxygen atoms and support species are considered. The methane dissociation requires reduced metal sites, but at elevated temperatures oxides of active species may be reduced by direct interaction with methane or from the reaction with $\mathrm{H}_{2}$ and $\mathrm{CO}$ (or C). The comparison of elementary reaction steps on Pt and Rh illustrates the fact that a key factor to produce hydrogen as primary product is a high activation energy barrier to the formation of $\mathrm{OH}$. Another essential property for the formation of $\mathrm{H}_{2}$ and $\mathrm{CO}$ as primary products is a low surface coverage of intermediates, such that the probability of $\mathrm{O}-\mathrm{H}, \mathrm{OH}-\mathrm{H}$ and $\mathrm{CO}-\mathrm{O}$ interactions is reduced.
\end{abstract}

Keywords: Catalytic partial oxidation, transition metal catalysts, mechanisms.

\section{INTRODUCTION}

Natural gas (NG), which is composed primarily of methane, is one of the most abundant, low-cost C-containing feedstocks available. NG reservoirs are large and widely spread, mainly located in Middle East and Russia. The estimated NG reserves rose from $5.1 \times 10^{14} \mathrm{ft}^{3}$ in 1997 to nearly $6.3 \times 10^{14} \mathrm{ft}^{3}$ in 2006 [1]. In addition, large amounts of NG are flared in refineries, chemical plants, oil wells and landfills. Flaring represents a pollution issue since it releases both $\mathrm{CO}_{2}$ and unburned $\mathrm{CH}_{4}$ green house gases into the atmosphere. Finding efficient and clean processes to exploit the NG reserves is critical to solve both environmental and energy-related issues. In spite of this, methane cannot be directly converted to useful chemicals or fuels and high temperature, multi-step processes proceeding via syngas are utilized for its conversion. This is primarily because the $\mathrm{C}-\mathrm{H}$ bonds of methane are strong and efficient catalysts have not been developed that can economically, selectively and directly convert methane to functionalized molecules.

Methane can be converted either directly via a one step process or indirectly via several steps into many downstream fuels and chemicals [2]. It should be pointed out that the direct conversion is still studied at a fundamental level and results in low reaction yields. Presently, the only economically available route for the conversion of methane

*Address correspondence to this author at the Advanced Materials and NanoResearch Center, Najran University, P.O. Box: 1988, Najran 11001, Saudi Arabia; Tel: +966 7542 8888; Fax: +966 7542 8887;

E-mail: Salehalsayari8@gmail.com into more valuable chemicals is via synthesis gas (also referred as syngas, a $\mathrm{H}_{2}-\mathrm{CO}$ mixture), followed by different processes to manufacture the desired chemical [3]. While the production of syngas is a required step in the indirect conversion of methane, it also accounts for a large part of the total investment costs in a large scale industrial plant. Therefore, much research has been devoted to the improvement and development of more efficient processes for the conversion of methane to syngas.

Syngas can be produced from methane via three reactions: (i), steam reforming; (ii), dry reforming (or $\mathrm{CO}_{2}$ reforming); and (iii), partial oxidation. To date, the only large-scale process for natural gas conversion is the endothermic reaction known as steam reforming (SRM, Eq. 1) which is also the major route for the production of $\mathrm{H}_{2}$ [47]:

$\mathrm{CH}_{4}+\mathrm{H}_{2} \mathrm{O} \rightarrow \mathrm{CO}+3 \mathrm{H}_{2} \quad \Delta \mathrm{H}_{\mathrm{r}}=+206 \mathrm{~kJ} / \mathrm{mol}$

In SRM, methane is converted with steam on supported $\mathrm{Ni}$ catalysts in a highly endothermic reaction to yield $\mathrm{H}_{2} / \mathrm{CO}$. The SRM reaction is conducted in large tubular reactors to achieve high temperatures needed for considerable syngas yields, making steam reforming a major energy consumer. Usually the steam reformer is followed by an additional water gas shift (Eq. 2) reactor to remove $\mathrm{CO}$ and increase the $\mathrm{H}_{2} / \mathrm{CO}$ ratio:

$\mathrm{CO}+\mathrm{H}_{2} \mathrm{O} \rightarrow \mathrm{CO}_{2}+\mathrm{H}_{2} \quad \Delta \mathrm{H}_{\mathrm{r}}=-41 \mathrm{~kJ} / \mathrm{mo}$

As the residence time inside the reactors lies in the range of $1 \mathrm{~s}$, large reactor volumes are necessary for high reactor throughputs. An alternative process for syngas formation is 
the exothermic catalytic methane partial oxidation (CPOM). In this process, methane is converted with oxygen or air to form $\mathrm{H}_{2}$ and $\mathrm{CO}$ at a ratio of $2(\mathrm{Eq} .3)$ in a one step reaction:

$\mathrm{CH}_{4}+1 / 2 \mathrm{O}_{2} \rightarrow \mathrm{CO}+2 \mathrm{H}_{2} \quad \Delta \mathrm{H}_{\mathrm{r}}=-36 \mathrm{~kJ} / \mathrm{mol}$

Due to the mild exothermicity of the partial oxidation, this reaction can be conducted autothermally. Furthermore, the $\mathrm{H}_{2} / \mathrm{CO}$ ratio of 2 is ideal for most downstream processes, making partial oxidation of methane a simple, one-step process. A non-catalytic partial oxidation process was developed by Texaco and Shell which results in high syngas yields at high temperature and pressures [2]. Problems related to the homogeneous process are excessive temperatures, long residence time as well as excessive coke formation, which strongly reduce the controllability of the reaction.

In the CPOM reaction, methane is converted with oxygen (or air) over noble metal (Pt, Rh, Ir, Pd) and non-noble metal (Ni, Co) catalysts to syngas in a single step process. Reaction 3 is characterized by very high autothermal temperatures exceeding $1000{ }^{\circ} \mathrm{C}$, which results in very high reaction rates and therefore very high space-time yields. The contact time needed for CPOM is extremely short ( $\tau=1-40 \mathrm{~ms})$, several orders of magnitude shorter than steam reforming. All these advantages allow compact and economic (low energy consumption) reactors, which promote a decentralized natural gas utilisation and syngas (or hydrogen) production, and make it a promising technology for the upcoming gas economy. CPOM has been studied extensively during the past decade. Many studies have focused on the reaction mechanism [2, 8]; reactor configurations [9-11]; reactor simulations [6, 12] as well as novel catalyst synthesis [13] to improve the process (i.e. increase reaction yields) efficiency.

\section{THERMODYNAMICS OF CPOM REACTION}

Reaction 3 indicates that synthesis gas can be obtained through a direct route. According to this reaction, production of syngas is theoretically possible at all temperatures once $\mathrm{CH}_{4}$ and $\mathrm{O}_{2}$ have been activated. But this is an oversimplified approach because other reactions such as reactions 1 and 2, and other oxidation reactions of $\mathrm{CH}_{4}, \mathrm{H}_{2}$ and $\mathrm{CO}$, decomposition of $\mathrm{CH}_{4}$ and $\mathrm{CO}$ may occur simultaneously. It is clear that all these reactions play important roles in the partial oxidation of methane, and therefore the product composition at the reactor exit is governed by or limited by the thermodynamic equilibrium of all possible species involved in the process. The equilibrium composition appears to be essential when discussing experimental results, and detailed thermodynamic analysis of the $\mathrm{CH}_{4} / \mathrm{O}_{2}$ (and/or $\mathrm{H}_{2} \mathrm{O}$ ) mixtures has been reported [9, 11, 12]. Fig. (1) shows the effect of temperature and pressure on a stoichiometric mixture of methane and oxygen $\left(\mathrm{CH}_{4}: \mathrm{O}_{2}=\right.$ $2: 1$ ) [9]. At increasing pressures, higher temperatures are required to obtain high conversion, and high selectivity to $\mathrm{H}_{2}$ and $\mathrm{CO}$. Thermodynamic calculations also revealed that feeding $\mathrm{CH}_{4} / \mathrm{O}_{2}$ mixtures at a ratio of 0.5 yields complete combustion products $\left(\mathrm{CO}_{2}\right.$ and $\left.\mathrm{H}_{2} \mathrm{O}\right)$, but $\mathrm{CH}_{4} / \mathrm{O}_{2}$ ratios above this limit produce both $\mathrm{H}_{2}$ and $\mathrm{CO}$ as major products.
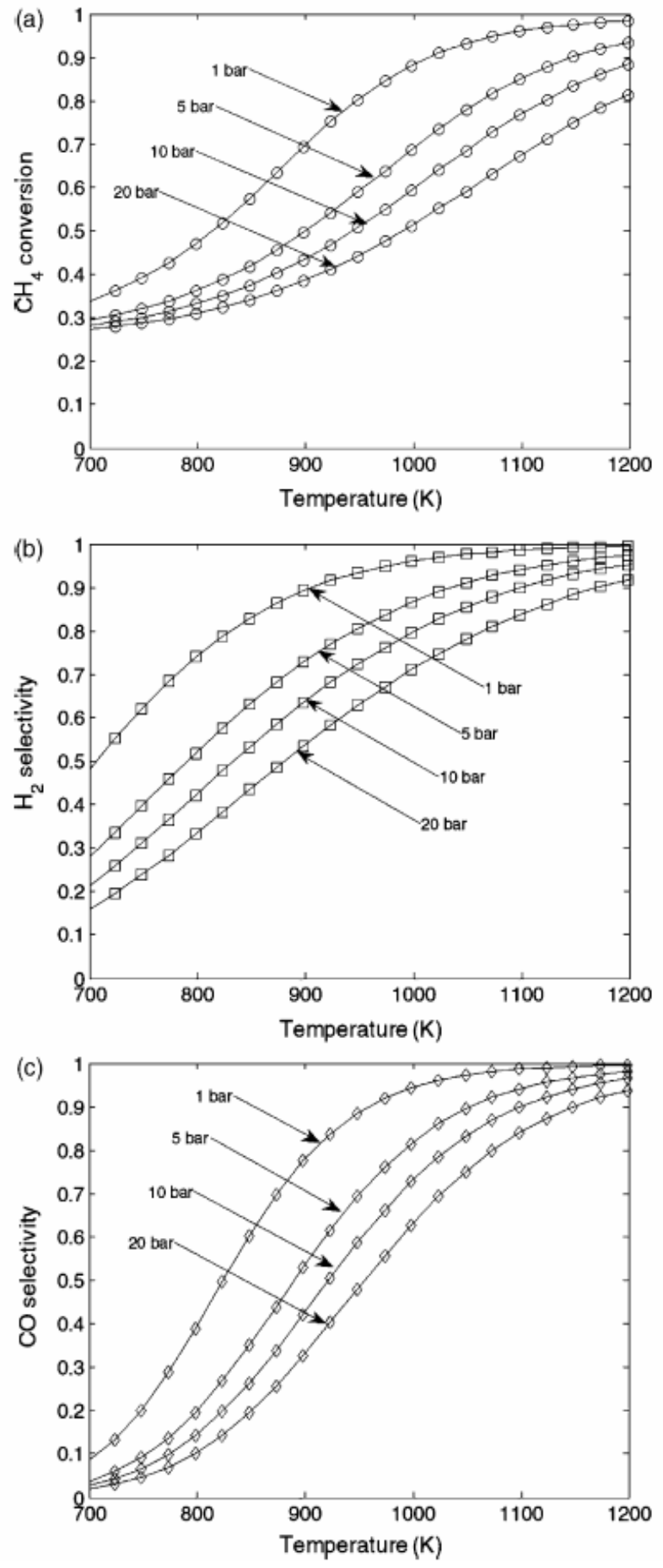

Fig. (1). Thermodynamic equilibrium as a function of the temperature at 1-20 bar using $\mathrm{CH}_{4} / \mathrm{O}_{2}=2: 1$ and air as oxidant. (a) The $\mathrm{CH}_{4}$ conversion, (b) the $\mathrm{H}_{2}$ selectivity and (c) the $\mathrm{CO}$ selectivity. From Enger et al. [6].

\section{REACTION MECHANISM OF CPOM REACTION}

Although many studies have been conducted with the aim to elucidate the mechanism of CPOM reaction, the mechanism by which $\mathrm{CO}$ and $\mathrm{H}_{2}$ are formed is not yet completely 
clarified. Two reaction mechanisms have been proposed: one is the "direct mechanism" in which $\mathrm{CH}_{4}$ and $\mathrm{O}_{2}$ react on the adsorbed state on the catalyst surface to yield $\mathrm{CO}$ and $\mathrm{H}_{2}$; the second one is the so-called "combustion-reforming mechanism". In this latter mechanism, $\mathrm{CH}_{4}$ and $\mathrm{O}_{2}$ first form $\mathrm{H}_{2} \mathrm{O}$ and $\mathrm{CO}_{2}$ (Eq. 4), and then dry (Eq. 5) and steam reforming (Eq. 1) reactions produce $\mathrm{CO}$ and $\mathrm{H}_{2}$. The reaction occurring according to the direct mechanism is shown in equation 3, however the reactions involved in the combustion-reforming mechanism are more complex as summarized in equations 1, 2, 4 and 5:

$\mathrm{CH}_{4}+2 \mathrm{O}_{2} \rightarrow \mathrm{CO}_{2}+2 \mathrm{H}_{2} \mathrm{O}\left(\Delta \mathrm{H}_{298}=-801 \mathrm{~kJ} / \mathrm{mol}\right)$
$\mathrm{CH}_{4}+\mathrm{CO}_{2} \rightarrow 2 \mathrm{CO}+2 \mathrm{H}_{2}\left(\Delta \mathrm{H}_{298}=+247 \mathrm{~kJ} / \mathrm{mol}\right)$

In addition to these reactions, other side reactions eventually occur. These include partial oxidations $\left(\mathrm{CH}_{4}+3 / 2\right.$ $\mathrm{O}_{2} \rightarrow \mathrm{CO}+2 \mathrm{H}_{2} \mathrm{O}$ and $\mathrm{CH}_{4}+\mathrm{O}_{2} \rightarrow \mathrm{CO}_{2}+2 \mathrm{H}_{2}$ ) and the formation of solid carbon by the Boudouard reaction (2 $\mathrm{CO}$ $\rightarrow \mathrm{C}+\mathrm{CO}_{2}$ ). Precise knowledge of the mechanism of $\mathrm{CPO}$ reaction is of vital importance because of the different thermal effects, as summarized above for the direct mechanism (Eq. 1) and combustion-reforming mechanism (Eqs. 2-5), which indeed affect both the design and heat management of industrial units.

\section{CATALYTIC SYSTEMS FOR CPO REACTION}

The CPO reaction has been investigated extensively for more than two decades. Before 1992 most studies were carried out at moderate or low space velocities at a residence time of $1 \mathrm{~s}$ or above [14]. However, later CPO has been carried out at least in the laboratory at very short contact times between 0.1 and $10 \mathrm{~ms}$ in some cases without preheating the feedstock and with no steam addition. Additional information regarding research, mainly of a fundamental nature, can be found for example in a series of papers by Schmidt et al. [15-17]. Supported noble metals and non-noble metal catalysts, mainly nickel-based catalysts, have been widely used in CPO reaction. An account of the catalysts and processes used to investigate the $\mathrm{CPO}$ reaction can be found in a review presented in $2008[6,18]$. Herewith, some recent developments in both catalysts and processes for CPO reaction are summarized.

\subsection{Noble Metals}

Noble metals have been widely studied in the CPO reaction because, despite their high cost, they show much higher activity than the cheaper Ni-based catalysts. On average, $\mathrm{Pt}$ is about 30.000 times more expensive than $\mathrm{Ni}$. Other noble metals such as $\mathrm{Pd}$, Ir and $\mathrm{Ru}$ are less expensive than $\mathrm{Pt}$ but still more expensive than $\mathrm{Ni}$ catalyst. If the loading of noble metal is low and is well dispersed on a substrate its high performance reduces significantly the price differences versus Ni. The group 8 noble metals are highly active in the CPO reaction, each of them showing their own characteristics. Research on promoters, supports modifiers and addition of a second metal that minimizes the loading of noble metal is going on.

\subsubsection{Pt Catalysts}

Several studies have been developed using Pt catalysts for the CPO reaction. Alumina supported Pt catalysts either promoted or non-promoted with $\mathrm{CeZr}$ were employed by
Silva et al. [19] in the CPO of methane. The promoted catalysts exhibited better activity and higher stability, while the non-promoted counterparts deactivated rapidly. The $\mathrm{Pt}$ loading was found to play an important role in the CPO reaction as a metal loading above $1.5 \mathrm{wt} \%$ was required to obtain good catalyst stability of both $\mathrm{Pt} / \mathrm{Al}$ and $\mathrm{Pt} / \mathrm{Al}(\mathrm{CeZr})$ catalysts. These authors proposed that the limiting reaction step is the C-H activation on the surface of Pt crystallites and the TOF rate increases with increasing $\mathrm{Pt}$ dispersion. While a high $\mathrm{Pt}$ dispersion increases the rate of $\mathrm{C}-\mathrm{H}$ bond cleavage, the oxygen storage capacity was not influenced by $\mathrm{Pt}$ dispersion and remained at moderately level. As a consequence, the rate of carbon removal from the Pt surface by oxygen transfer is not high enough and catalyst becomes deactivated by carbon accumulation. These results strongly suggest that the mechanism of the CPO reaction proceeds through a two-steps processes and that the CeZr-promoted 1.5Pt/Al catalyst displays the best performance in the target reaction. The high cost of $\mathrm{Pt}$ is a limit for the commercial application of these catalysts therefore developments to decrease Pt loading are imperative.

Attempts to overcome the limited high-temperature stability of Pt crystallites were successful by anchoring them on a hexa-aluminate matrix [20]. The combination of the high activity of $\mathrm{Pt}$ particles with excellent thermal stability of hexa-aluminate makes the Pt-BHA formulation a good catalyst candidate to be employed in the $\mathrm{CPO}$ reaction. Deposition of Pt-BHA catalysts in pre-shaped structures such as monoliths, foams and felts resulted particularly suited for practical applications. As compared to the reference catalysts, both Pt-BHA coated alumina foams and silica felts displayed still better $\mathrm{CH}_{4}$ conversion and $\mathrm{H}_{2}$ selectivity for Pt loadings almost one order of magnitude lower. In addition, the $25 \mathrm{~h}$ of catalyst testing demonstrated a good stability, although it is better when Pt-loading increases. These results indicate that the strategy followed by deposition of Pt-BHA catalysts in pre-shaped substrates while decreasing Pt loading by one order of magnitude represents a step ahead towards the use of these catalysts in practical applications.

The stability of zirconia supported catalysts calcined in air and also using plasma treatment was reported by Zhu et al. [21]. Both catalysts showed the same $\mathrm{CH}_{4}$ conversion of $74 \%$ and $\mathrm{H}_{2}$ and $\mathrm{CO}$ selectivity of 95 and $90 \%$, respectively, at a reaction temperature of $800{ }^{\circ} \mathrm{C}$ and a $\mathrm{CH}_{4}: \mathrm{O}_{2}$ molar ratio of 2 in the feed. However, both catalysts became deactivated upon stream operation, this being more severe for the calcined catalysts. Thermo-gravimetric experiments revealed that carbon deposition is not the reason for deactivation, instead Pt sintering was found to be the cause of activity drop. It was suggested that $\mathrm{Pt}$ atoms form a volatile $\mathrm{PtO}_{2}$ species which move across the catalyst surface and then is reduced and sinterized in larger Pt crystallites.

\subsubsection{Rh Catalysts}

Supported rhodium catalysts have been widely used in the CPO reaction even though $\mathrm{Rh}$ is the most expensive among the noble metals. Therefore precise design of $\mathrm{Rh}$ catalysts is imperative with the objective to minimizing metal loading while maintaining highest performance. Spatially resolved measurements on a $10 \mathrm{~mm}$ length $\mathrm{Rh} / \mathrm{Al}_{2} \mathrm{O}_{3}$ monolith were reported by Horn et al. [22] using a 
$10 \mathrm{~mm}$ long $\mathrm{Rh} / \mathrm{Al}_{2} \mathrm{O}_{3}$ monolith. In these experiments a capillary was connected to a mass spectrometer which allows get a resolution of about $0.3 \mathrm{~mm}$. For the different $\mathrm{CH}_{4} / \mathrm{O}_{2}$ ratios explored $\left(\mathrm{CH}_{4} / \mathrm{O}_{2}=0.7,1.0,1.3\right)$, the conversion of oxygen was completed within the $2 \mathrm{~mm}$ of the catalyst entrance. Products measured along the monolith were $\mathrm{CO}_{2}$, $\mathrm{H}_{2} \mathrm{O}$, $\mathrm{CO}$ and $\mathrm{H}_{2}$ however the conversion of oxygen was completed in the presence of the catalyst (see Fig. 2) $\mathrm{H}_{2} \mathrm{O}$ was also observed in the presence of the catalyst indicating back diffusion of $\mathrm{H}_{2}$ which reacts with oxygen to produce the water. The reaction mechanism was also studied by decoupling the chemistry from the temperature change, as changes in these parameters occur at time scales in the region $10^{-3}-10^{0} \mathrm{~s}$, respectively. By switching between a lean $\left(\mathrm{CH}_{4}: \mathrm{O}_{2}=0.6\right)$ and a rich $\left(\mathrm{CH}_{4} / \mathrm{O}_{2}=1: 4\right)$ feed, the transient behaviour of integral $\mathrm{H}_{2}$ and $\mathrm{CO}$ production was monitored by a mass spectrometer [23]. For $\mathrm{CH}_{4} / \mathrm{O}_{2}=0.6 \rightarrow 1.4$ the activation energy for $\mathrm{H}_{2}$ and $\mathrm{CO}$ formation were 23 and 13 $\mathrm{kJ} / \mathrm{mol}$, respectively, whereas for $1.4 \rightarrow 0.6$ the activation energy for $\mathrm{H}_{2}$ formation was $37 \mathrm{~kJ} / \mathrm{mol}$ in the low temperature range below $903 \mathrm{~K}$, and it was $9 \mathrm{~kJ} / \mathrm{mol}$ in the high temperature range above $983 \mathrm{~K}$. Activation energy for $\mathrm{CO}$ formation was 20 and $2 \mathrm{~kJ} / \mathrm{mol}$ in the same temperature regions, respectively. Such integral values can 't be compared to actual activation energies of elementary reactions, but as the formation of $\mathrm{H}_{2}$ has a stronger temperature dependence than $\mathrm{CO}$, the rate determining steps for the formation of $\mathrm{H}_{2}$ and $\mathrm{CO}$ appear to be different.

The effect of $\mathrm{Rh}$ loading in supported catalysts on their performance in the CPO reaction was reported by Li et al. [24]. These authors reported that the ignition temperature for the CPO reaction decreases as expected with increasing Rhloading. The behaviour of the catalysts in the target reaction was highlighted by running catalytic tests at constant temperature, within the $600-850{ }^{\circ} \mathrm{C}$ temperature interval. At the lowest reaction temperature, the $0.25 \mathrm{wt} \% \quad \mathrm{Rh} / \mathrm{Al}_{2} \mathrm{O}_{3}$ catalyst showed an oscillatory behaviour. When $\mathrm{CH}_{4}$ increases a parallel increase of the selectivity towards $\mathrm{H}_{2}$ and $\mathrm{CO}$ is observed, while a drop in $\mathrm{CH}_{4}$ conversion is accompanied by an increase of $\mathrm{CO}_{2}$ selectivity. This particular behaviour can be explained in terms of the periodic oxidation and reduction of $\mathrm{Rh}$ particles during $\mathrm{CPO}$ reaction. Temperature-programmed reduction and oxygen desorption experiments revealed that different Rh-species remain on the catalyst surface: (i), RhOx oxides weakly interacting ith the surface and reduced at low temperature; (ii), $\mathrm{Rh}^{\mathrm{A}} \mathrm{Ox}$ interacting with the alumina substrate and reduced at low temperature; and (iii), $\mathrm{Rh}\left(\mathrm{AlO}_{2}\right)_{\mathrm{x}}$ species reduced at temperatures as high as $500{ }^{\circ} \mathrm{C}$. The $\mathrm{Rh}-\mathrm{O}$ bonds in the catalyst with $\mathrm{Rh}$ loadings $\leq 0.25 \mathrm{wt} \%$ are highly stable and difficult to reduce by hydrogen. The speciation and reducibility of all these $\mathrm{Rh}$ species are responsible for the oscillatory behaviour of these catalysts in the CPO reaction when operating at low reaction temperatures but it disappears when reaction is conducted at $850{ }^{\circ} \mathrm{C}$ at which all $\mathrm{Rh}$ species are in the metallic state.

Incorporation of $\mathrm{Rh}$ onto alumina substrate by different procedures (impregnation, grafting and chemical vapour deposition) resulted in catalysts with different structures [25]. Due to inhomogeneities in the active phase distribution, some differences in the performance of these catalysts were
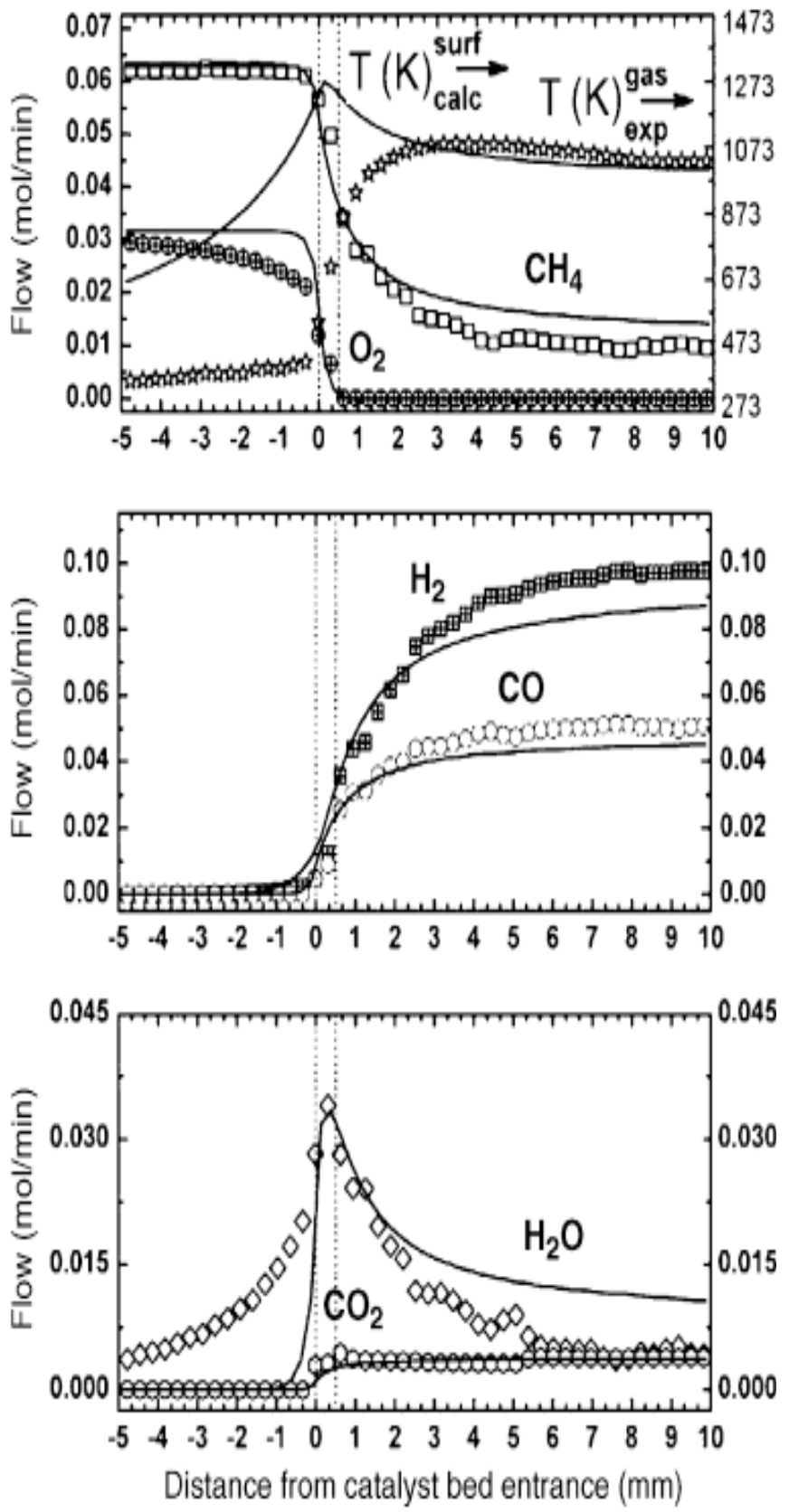

Fig. (2). Partial oxidation of methane over a $10 \mathrm{~mm}$ Rh-coated $\alpha$ $\mathrm{Al}_{2} \mathrm{O}_{3}$, showing species and temperature profiles for a total flow 5 $\mathrm{L} / \mathrm{min}, \mathrm{C} / \mathrm{O}=1.0$, where the symbols are experimental data and the solid lines are from a simulation based on a $2 \mathrm{D}$ porous model with 38 surface reactions [22].

observed at short reaction times but at long periods onstream all catalysts showed similar performance. Some surface and structural characterisations demonstrated that the heterogeneity of the surface is strongly dependent on the preparation procedure and minimized by the chemical vapour deposition method, however when CPO reaction is conducted at high reaction temperatures the surface becomes reconstructed leading to a similar surface structure independent on the preparation methodology followed.

Since $\mathrm{Rh}$ catalysts are highly active, selective and stable in the course of the $\mathrm{CPO}$ reaction, some studies were 
concentrated in the mechanism of the reaction. It is very important to know whether a two step combustion-reforming mechanism is operative because a hot spot should be developed at the front end of the catalyst bed due to the $\mathrm{CH}_{4}$ combustion that can locally increase temperature by more than $100^{\circ} \mathrm{C}$. Donazzi et al. [26] employed an annular reactor to perform a kinetic analysis on a $4 \mathrm{wt} \% \mathrm{Rh} / \mathrm{Al}_{2} \mathrm{O}_{3}$ catalyst. Under both non-diluted and $\mathrm{N}_{2}$-diluted $\mathrm{CH}_{4}+\mathrm{O}_{2}$ feeds, the formation of hot spots was detected, which means development of a first exothermic reaction. The kinetic scheme revealed that the steam reforming is delayed by the presence of $\mathrm{O}_{2}$ in the feed. Direct and reverse water gas-shift (WGS and RWGS) reactions have different roles in the CPO process: WGS is fast and limited by equilibrium while RWGS is negligible. In addition, the kinetic roles of $\mathrm{H}_{2}$ and $\mathrm{CO}$ change with dilution, they are negligible with diluted feeds while their oxidations go against WGS equilibration and control the $\mathrm{H}_{2} / \mathrm{CO}$ ratio obtained.

An isotopic tracer study was conducted on Rh catalysts supported on zirconia-doped ceria with the objective to identify from where the oxygen oxidizing $\mathrm{CH}_{4}$ into $\mathrm{CO}$ comes [27]. For this purpose, a $1 \mathrm{wt} \% \mathrm{Rh}$ catalyst supported on $\mathrm{Ce}_{0.56} \mathrm{Zr}_{0.44} \mathrm{O}_{2}$ substrate and a $1 \mathrm{wt} \% \mathrm{Rh}$ catalyst supported on alumina as reference were employed. Isothermal isotopic exchange experiments revealed appearance of three different O-species: ${ }^{16} \mathrm{O}-{ }^{16} \mathrm{O},{ }^{18} \mathrm{O}-{ }^{18} \mathrm{O}$ and ${ }^{16} \mathrm{O}-{ }^{18} \mathrm{O}$. Since only ${ }^{18} \mathrm{O}-{ }^{18} \mathrm{O}$ labelled oxygen was fed at the reactor inlet, the appearance of ${ }^{16} \mathrm{O}-{ }^{18} \mathrm{O}$ exchanged molecules is a proof that ${ }^{18} \mathrm{O}-{ }^{18} \mathrm{O}$ adsorbs dissociatively in the atomic form on the catalyst surface and there is an exchange between the gas phase and catalyst surface. This study also revealed that in the course of CPO reaction $\mathrm{CH}_{4}$ is selectively oxidized by lattice oxygen by lattice $\mathrm{O}^{2-}$ ions from the $\mathrm{Ce}-\mathrm{Zr}$-O support to form $\mathrm{CO}$. In addition, blank experiments with the $\mathrm{Ce}-\mathrm{Zr}-\mathrm{O}$ support alone indicated that the maximum exchange with $\mathrm{Rh}$ particles deposited on the surface occurs at much lower temperature $\left(250^{\circ} \mathrm{C}\right)$.

In another study these authors investigated the reducibility and redox cycles of $\mathrm{Rh}$ catalysts supported on M-doped ceria substrates ( $\mathrm{M}=\mathrm{La}, \mathrm{Zr}$ and $\mathrm{Gd}$ ) [28]. Among these promoters, zirconia was found to strongly promote the reduction of $\mathrm{Rh}$ and the interaction of $\mathrm{Rh}$ particles and ceria surface. From $\mathrm{CH}_{4}$-temperature programmed reduction experiments, it was revealed that $\mathrm{H}_{2}$ releases by the oxidation of $\mathrm{CH}_{4}$ on both the cubic and tetragonal ceria phases. The performance of $\mathrm{Zr}$-doped catalyst was also investigated by means of repeated oxidation cycles. Using constant feed conditions, repeated cycles led to a progressive increase of the quantity of $\mathrm{H}_{2}$ produced. This trend runs in parallel with the $\mathrm{O}_{2}$ uptake measured from temperature programmed oxidation experiments. The suggested mechanism takes into account that $\mathrm{CO}_{2}$ is formed before $\mathrm{CO}$ and its concentration decreases as $\mathrm{CO}$ concentration increases, thus being inferred that $\mathrm{CO}$ forms at the expense of $\mathrm{CO}_{2}$ consumed.

\subsection{3. $R$ u Catalysts}

Ruthenium catalysts are quite interesting because they are not only active and selective in the CPO reaction but also the least expensive among the noble metals. Notwithstanding, the stability of $\mathrm{Ru}$ catalysts supported on alumina and silica is limited [29]. Using a Ce-Zr-O substrate, $\mathrm{Ru}$ catalysts showed only moderate selectivity to syngas production because the support catalyses deep oxidation. The catalysts exhibited changes in the oxidation state of rhodium particles which were reflected in hysteresis cycles during operation: in the metallic state $\mathrm{Ru}$ operates through a direct mechanism, however the oxidized $\mathrm{RhO}_{\mathrm{x}}$ species favor the combustion-reforming mechanism. Some improvement of the performance of $\mathrm{Ru}$ catalysts was obtained by preparing $\mathrm{Ru}$ catalysts by the microemulsion methodology [30]. These catalysts showed a stronger Ru-support interaction and better performance, at $600{ }^{\circ} \mathrm{C}$ the $\mathrm{CH}_{4}$ conversion approached equilibrium value whereas $\mathrm{H}_{2}$ and $\mathrm{CO}$ selectivity reached almost $100 \%$ at temperatures above $700{ }^{\circ} \mathrm{C}$. Another approach undertaken to stabilize $\mathrm{Ru}$ particles was achieved by incorporation of Pt to catalyst composition [31]. In these Pt-modified $\mathrm{Ru}$ catalysts hysteresis cycles almost disappeared even though shorter space velocities were required to reach the same conversion level than with the monometallic $\mathrm{Ru}$ catalyst. This catalyst exhibited good stability and reaction followed the indirect combustionreforming mechanism. A similar indirect reaction mechanism was proposed by Choque et al. [32] by using titania- and titania-zirconia-supported $\mathrm{Ru}$ catalysts prepared by a sol-gel methodology. Activity tests performed at low $\mathrm{CH}_{4}$ conversions evidenced that the initial presence of $\mathrm{RuO}_{2}$ species catalyses the $\mathrm{CH}_{4}$ combustion whereas the $\mathrm{Ru}$ metal which is developed in the course of the reaction produces syngas.

An oscillatory behaviour of the $\mathrm{CPO}$ reaction was reported by Wang et al. [33] when conducting the reaction on silica- and alumina-supported catalysts. The $\mathrm{Ru} / \mathrm{Al}_{2} \mathrm{O}_{3}$ catalysts showed two types of oscillations while the $\mathrm{Ru} / \mathrm{SiO}_{2}$ counterparts produced only one type of oscillations. The first type of oscillation is produced by the ruthenium species which interact weakly with alumina surface. The oscillation is the result of the periodic transition of a small fraction of $\mathrm{Ru}$ species on the surface of metallic Ru0 particles from the reduced to the oxidized state during the CPO reaction. The second type of oscillation is related to the $\mathrm{Ru}$ species which strongly interact with the alumina surface. The behaviour of these species switching back and forth the oxidized to metallic state is responsible for the oscillation of activity of $\mathrm{Ru} / \mathrm{Al}_{2} \mathrm{O}_{3}$ catalysts in the temperature range of $600{ }^{\circ} \mathrm{C}$ to 800 ${ }^{\circ} \mathrm{C}$. Indeed, these cyclic transformations are the result of temperature variations caused by the contribution of the strongly exothermic $\mathrm{CH}_{4}$ combustion and endothermic $\mathrm{CH}_{4}$ reforming (with $\mathrm{H}_{2} \mathrm{O}$ and/or $\mathrm{CO}_{2}$ ) reactions, which are favoured by the $\mathrm{RuO}_{\mathrm{x}}$ and $\mathrm{Ru}^{0}$ sites, respectively. Thus, the principal reaction pathway for syngas production via $\mathrm{CPO}$ reaction on $\mathrm{Ru} / \mathrm{Al}_{2} \mathrm{O}_{3}$ catalyst is the indirect combustionreforming mechanism.

\subsubsection{Palladium}

Palladium catalysts are known to be highly active for methane combustion; however the limited stability of the catalysts at high temperatures makes them unsuited for the $\mathrm{CPO}$ reaction. This barrier can be overcome by adding rare earths and/or alkaline earth oxides to catalyst formulations. Ryu et al. [34] studied the effect of adding $\mathrm{Ce}, \mathrm{Ba}$ and $\mathrm{Sr}$ oxides to a $\mathrm{Pd} / \mathrm{Al}_{2} \mathrm{O}_{3}$ catalyst on the performance for the $\mathrm{CPO}$ reaction. The promoted catalysts showed ignition temperatures higher than that of the non-doped $\mathrm{Pd} / \mathrm{Al}_{2} \mathrm{O}_{3}$ catalyst although they quickly approached the equilibrium 
methane conversion. In addition, $\mathrm{H}_{2}$ and $\mathrm{CO}$ selectivities remained always high, typically $60-90 \%$ and $84-96 \%$ at 700 ${ }^{\circ} \mathrm{C}$. Aged catalysts showed not only a drop in activity but also an increase in the ignition temperature. However, the $\mathrm{Ce}-\mathrm{Ba}-\mathrm{Sr}$ promoted catalyst maintained a high activity, comparable to that of the fresh counterpart. In this promoted catalyst, $\mathrm{BaO}$ confers a higher stability of the substrate, whereas $\mathrm{CeO}_{2}$ incorporation enhances both activity and stability of the catalyst. The addition of a small amount of $\mathrm{SrO}$ to the CeBaAl substrate resulted in an enhancement of $\mathrm{Pd}$ dispersion and also in the stability of Pf particles, so that the extent of the deactivation of metal particles by sintering was minimized.

\subsection{Ni-Based Catalysts}

Nickel is doubtless the most widely used active phase for partial oxidation of methane. As compared to noble metals, nickel is inexpensive, its cost ranges from 7 to $35 € / \mathrm{kg}$ along the last years [35]. However, Ni suffers from deactivation during on-stream as a consequence of several processes such as sintering, carbon deposition, solid state reactions and volatilisation as metal carbonyls.

\subsubsection{Nickel on Conventional Supports}

The need of a support for the active metal is a key requirement when developing catalyst for the CPO reaction. The influence of the support on the catalyst performance is revealed when supported catalysts are compared with physical mixtures of components [36]. For instance, the catalyst obtained by mixing $\mathrm{NiO}$ and $\mathrm{Al}_{2} \mathrm{O}_{3}$ gives very low activity, but this activity increases with time due to the migration of nickel through the alumina phase. $\mathrm{Al}_{2} \mathrm{O}_{3}$ is the support most widely used owing to its stability at high temperature and under strong reaction conditions and to its availability. Notwithstanding, it is not the most suitable carrier because the supported metal phases become deactivated by sintering and coke deposition and other alternatives have been suggested. By comparing $\mathrm{Ni} / \mathrm{Al}_{2} \mathrm{O}_{3}$ with $\mathrm{Ni} / \mathrm{La}_{2} \mathrm{O}_{3}$ catalysts, Tsipouriari et al. [37] found that the alumina-supported catalysts become deactivated by accumulation carbon with the time on-stream. On the contrary, the lanthana supported catalyst also accumulates carbon but the quantity of the carbon deposit is constant and does not increase with time. The $\mathrm{NiAl}_{2} \mathrm{O}_{4}$ phase, which is difficult to be reduced, is not active for the reforming reaction but it is active for carbon formation. Similarly, Barbero et al. [38] used $\mathrm{LaNiO}_{3-\delta}$ as catalyst precursors for the CPO reaction and found that the better performance of lanthana-supported catalysts is assigned to the formation of a deficient perovskite $\mathrm{LaNiO}_{3-\delta}$, that -after reductionmaintains the $\mathrm{Ni}$ particles highly dispersed in the $\mathrm{La}_{2} \mathrm{O}_{3}$ matrix, with stronger resistance to sintering and carbon formation.

The same effect is detected when an $\mathrm{MgO}$ support is used, due to the formation of a solid solution $\left(\mathrm{Mg}_{1-\mathrm{x}} \mathrm{Ni}_{\mathrm{x}} \mathrm{O}\right)$ between nickel and magnesia [39]. $\mathrm{Ni} / \mathrm{MgO}$ catalysts are more active and even more stable than the parent $\mathrm{Ni} / \mathrm{La}_{2} \mathrm{O}_{3}$ catalysts. The reason for the excellent performance of $\mathrm{Ni} / \mathrm{MgO}$ catalyst lies in the formation of a cubic $\left(\mathrm{Mg}_{1-\mathrm{x}} \mathrm{Ni}_{\mathrm{x}} \mathrm{O}\right)$ solid solution in which the $\mathrm{Ni}^{2+}$ ions are highly stable against reduction even at temperatures as high as $1273 \mathrm{~K}$. Under operation, the small fraction of nickel reduced remains highly dispersed and in close interaction with the basic $\mathrm{MgO}$ substrate, this structure being specially suited for syngas production from methane [40]. In contrast, the use of $\mathrm{ZrO}_{2}$ as a support is not effective, since its low interaction with nickel produces large metal particles that easily deactivate.

The effect of the support has also been investigated in other active metals, and the tendencies are not the same in all cases. Bitter et al. [41] found that the trend in stability on supported platinum was $\mathrm{ZrO}_{2}>\mathrm{TiO}_{2}>\mathrm{Al}_{2} \mathrm{O}_{3}$. This trend was different in supported nickel, $\mathrm{Al}_{2} \mathrm{O}_{3}$ supported nickel being more stable than the corresponding $\mathrm{TiO}_{2}$ supported catalyst [36]. In the case of Pt, there is no evidence of sintering, and deactivation is produced by blocking of the active centres by carbon. The support in this case has a very active role, and for the reducible oxides $\left(\mathrm{TiO}_{2}, \mathrm{ZrO}_{2}\right)$ small oxide crystallites decorate the metal particle, producing a better control of carbon formation at this interface. In addition, it has been reported that $\mathrm{Pt} / \mathrm{Ce}_{\mathrm{x}} \mathrm{Zr}_{(1-\mathrm{x})} \mathrm{O}_{2}$ catalysts are more active, stable and selective than the $\mathrm{CeO}_{2}$ and $\mathrm{ZrO}_{2}$ supported counterparts. The higher reducibility and oxygen storage/release capacity of $\mathrm{Pt} / \mathrm{Ce}_{\mathrm{x}} \mathrm{Zr}_{(1-\mathrm{x})} \mathrm{O}_{2}$ catalysts promotes the continuous removal of carbonaceous deposits from the active sites, which takes place at the metal-support interfacial perimeter [42]. For $\mathrm{Al}_{2} \mathrm{O}_{3^{-}}, \mathrm{ZrO}_{2^{-}}, \mathrm{CeO}_{2^{-}}$and $\mathrm{Y}_{2} \mathrm{O}_{3^{-}}$ supported $\mathrm{Pt}$ catalysts, the $\mathrm{Pt} / \mathrm{CeO}_{2}$ system showed the highest stability in the POM reaction due to the higher reducibility and oxygen storage/release capacity which allowed a continuous removal of carbonaceous deposits from the active sites [43]. This reaction has also been studied over $\mathrm{Rh}$ supported on Ce oxide with $\mathrm{Zr}, \mathrm{Gd}$ and La. Obtained results indicate that the type of doped-ceria support and its reducibility played an important role in catalyst activity. It was observed that doping $\mathrm{CeO}_{2}$ with $\mathrm{Zr}$, rather than with $\mathrm{La}$ or Gd causes an enhanced reducibility of $\mathrm{Rh} /$ supported-ceria catalysts which increases the activity of the system for the production of syngas [44].

\subsubsection{Promoters}

As the temperature at which the methane partial oxidation occurs is rather high, typically above $700{ }^{\circ} \mathrm{C}$, the catalysts become deactivated after some time on-stream. The stability of catalysts can be improved not only by the use of an appropriate support, but also by doping the supported catalyst with other added metals. The most typical way of promoting nickel catalysts is by the use of alkaline and alkaline earth metals. Chang et al. [45] explained the promotion with $\mathrm{K}$ and $\mathrm{Ca}$ of $\mathrm{Ni} / \mathrm{NaZSM}-5$ zeolite by the formation of surface carbonates, produced by the interaction of $\mathrm{CO}_{2}$ with the alkaline promoters, which hinder the formation of inactive coke or scavenge carbon from the surface Ni species. By means of isotopic effect experiments, these authors also observed that the activation of $\mathrm{CH}_{4}$ at the nickel surface is not the rate-determining step in the direct oxidation mechanism: the rate is determined by the surface reaction between adsorbed $\mathrm{O}_{\mathrm{ads}}$ and $\mathrm{C}_{\mathrm{ads}}$ species.

Zirconia [46], lanthana [47], ceria [48] and ceria-zirconia [49] oxides have been recently reported as promoters of methane reforming reactions. Incorporation of a $5 \mathrm{wt} \% \mathrm{ZrO}_{2}$ to a base $\mathrm{Ni} / \mathrm{SiO}_{2}$ catalyst resulted in excellent performance for the $\mathrm{CPO}$ reaction $\mathrm{O}_{2}$ mixture in a fluidized-bed reactor. A conversion of $\mathrm{CH}_{4}$ near thermodynamic equilibrium and low $\mathrm{H}_{2} / \mathrm{CO}$ ratio $\left(1<\mathrm{H}_{2} / \mathrm{CO}<2\right)$ was obtained without catalyst 
deactivation for $10 \mathrm{~h}$ on-stream, in a most energy efficient and safe manner. It has been argued that $\mathrm{ZrO}_{2}$ could promote the dispersion of $\mathrm{Ni}$ on the silica substrate, which has a direct effect on its reduction behaviour, $\mathrm{CO}_{2}$ adsorption and catalytic performance [46]. For $\mathrm{Ni} / \mathrm{Ce}-\mathrm{Zr}$ catalysts with $\mathrm{Ni}$ loadings between 9 and $50 \mathrm{wt} \%$, Larrondo et al. [49] showed that the reduction of nickel species into the metal phase is necessary for the CPO reaction to occur otherwise the catalysts behave mainly as combustion catalysts. If catalysts were prereduced prior to reaction, they oxidize selectively $\mathrm{CH}_{4}$ into syngas at lower temperatures, in a range where the oxidized catalysts only produce $\mathrm{CO}_{2}$ and $\mathrm{H}_{2} \mathrm{O}$. Although these catalysts were tested for only $5 \mathrm{~h}$ on-stream, no carbon was deposited on the surface suggesting that the mixed Ce$\mathrm{Zr}$ oxide substrate contributes to the removal of the carbonaceous species as a consequence of the high oxygen mobility in the support.

The promotion effect of lanthana on the structural and catalytic properties of $\mathrm{Pt} / \mathrm{La}-\mathrm{Al}$ catalysts was studied in methane steam reforming and methane partial oxidation reactions [47]. While the La-free $\mathrm{Pt} / \mathrm{Al}_{2} \mathrm{O}_{3}$ catalyst became strongly deactivated during the methane partial oxidation reaction, the La-promoted counterpart displayed much better stability. The increase of activity observed during the reaction was ascribed to the ability of the $\left[\mathrm{LaPt}_{\mathrm{x}} \mathrm{O}\right] \mathrm{Pt}^{0}$-like species to promote the gasification of coke. According to this cleaning mechanism, active sites remain accessible to $\mathrm{CH}_{4}$ molecules [47]. Similarly, ceria doping of supported Rh catalysts resulted in significant improvement of methane conversion and syngas selectivity during the methane partial oxidation, which could be related to higher noble metal dispersion [48]. For the cerium (1 wt\%)-doped $\mathrm{Pt} / \mathrm{Al}_{2} \mathrm{O}_{3}$ catalyst, the good activity and stability in the partial oxidation of methane was associated to its higher metal dispersion, higher oxygen storage capacity and larger degree of alumina coverage by the $\mathrm{CeZrO}_{2}$ moiety which make the carbon cleaning mechanism effective [50].

\subsubsection{Perovskite Precursors}

Perovskite oxides have also been extensively used as precursors of supported metal catalysts. Perovskites are mixed oxides with a general stoichiometry of $\mathrm{ABO}_{3}$, where $\mathrm{A}$ and $\mathrm{B}$ can be partially substituted by other metals. Most of the perovskites studied have a lanthanide and/or alkalineearth metal in the A site, and the active metal in the B site. After reduction, a highly dispersed metal supported in the lanthanide or alkaline earth oxide is obtained. As an illustrative example, Lago et al. [51] analysed the behaviour of $\mathrm{LnCoO}_{3}$ systems ( $\left.\mathrm{Ln}=\mathrm{La}, \mathrm{Pr}, \mathrm{Nd}, \mathrm{Sm}, \mathrm{Gd}\right)$. In this series, the reduced Gd-Co perovskite had the highest activity for $\mathrm{CPO}$, followed by $\mathrm{Sm}>\mathrm{Nd}>\mathrm{Pr}$. The reduced La-Co perovskite was only active for the combustion of methane. XPS analysis of the used catalysts revealed that $\mathrm{Co}$ is oxidised to form the original $\mathrm{LaCoO}_{3}$ perovskite under the reaction conditions used. In the $\mathrm{Nd}-\mathrm{Co}$ system, cobalt is partially oxidised, and in Gd-Co and Sm-Co catalysts cobalt remains reduced. TPR analysis of the perovskites reveals that reduction is produced in two steps $\left(\mathrm{LnCoO}_{3} \rightarrow\right.$ $\left.\mathrm{LnCoO}_{2.5} \rightarrow \mathrm{Co} / \mathrm{Ln}_{2} \mathrm{O}_{3}\right)$; that this reduction is reversible, and that the reduction temperature depends on the lanthanide employed. The most stable perovskite, $\mathrm{LaCoO}_{3}$, is difficult to reduce and is very easily reversed to the oxidised state. It may be concluded that very stable perovskites are not appropriate precursors of metal supported catalysts, since the metallic particles will tend to reverse to the perovskite phase.

Iron incorporated in perovskite structures also showed activity in the CPO reaction. Dai et al. [52] reported that $\mathrm{LaFeO}_{3}, \quad \mathrm{La}_{0.8} \mathrm{Sr}_{0.2} \mathrm{FeO}_{3} \quad$ and $\mathrm{La}_{0.8} \mathrm{Sr}_{0.2} \mathrm{Fe}_{0.9} \mathrm{Co} 0 .{ }_{1} \mathrm{O}_{3}$ perovskites produced syngas when $\mathrm{CH}_{4}$ is fed in the absence of oxidant. The oxygen atoms required for $\mathrm{CO}$ formation come from the perovskite lattice. The catalysts are first oxidized before testing and accumulate oxygen in their structure due to their high oxygen storage capability which tends to increase with the number of redox cycles. At $900{ }^{\circ} \mathrm{C}$, $\mathrm{CH}_{4}$ conversion above $80 \%$ was somewhat below the equilibrium value at atmospheric pressure while $\mathrm{CO}$ selectivity approached $100 \%$ without adding oxygen to the feed stream. After 16 redox cycles, $\mathrm{La}_{0.8} \mathrm{Sr}_{0.2} \mathrm{Fe}_{0.9} \mathrm{Co} 0 .{ }_{1} \mathrm{O}_{3}$ experienced a sudden drop in $\mathrm{CO}$ selectivity while $\mathrm{CH}_{4}$ conversion remained essentially constant. Structural analyses of the fresh and used samples revealed that the provskite structure is lost in the course of the CPO reaction and new phases are developed, while the other perovskites kept intact their original structure after main stream operation.

Perovskite structures of the type $\mathrm{CaTiO}_{3}, \mathrm{SrTiO}_{3}, \mathrm{BaTiO}_{3}$ and $\mathrm{LaAlO}_{3}$ have been used as supports by Shishido et al . [53] to prepare supported nickel catalysts. All these supported $\mathrm{Ni}$ catalysts showed better performance than a $\mathrm{Ni} / \mathrm{Al}_{2} \mathrm{O}_{3}$ reference catalyst. Specifically, the $\mathrm{Ni} / \mathrm{LaAlO}_{3}$ was the most active catalyst which suppressed the hot spot formation at the catalyst inlet, keeping the peak temperature about $100-150{ }^{\circ} \mathrm{C}$ lower than the other perovskite based catalysts. This is due to a larger overlap between the oxidation and the reforming zone where exothermic and endothermic reactions occur, respectively.

It has been shown that the $\mathrm{LaNiO}_{3}$ perovskite renders small $\mathrm{Ni}$ particles deposited on a $\mathrm{La}_{2} \mathrm{O}_{3}$ substrate upon reduction. The resulting catalyst exhibited over $90 \% \mathrm{CH}_{4}$ conversion at $800{ }^{\circ} \mathrm{C}$ with $\mathrm{H}_{2}$ and $\mathrm{CO}$ production at a ratio close to 2:1 [54]. Water and $\mathrm{CO}_{2}$ production was negligible after an initial phase where they were major products. This behaviour is related to the nature of nickel species: at the beginning of the reaction when an important fraction of nickel remains in the oxidized state $\left(\mathrm{Ni}^{2+}\right)$ the catalyst acts as combustion catalysts, whereas syngas is produced at longer reaction times when these $\mathrm{Ni}^{2+}$ species become reduced by the $\mathrm{H}_{2}$ generated in the course of the CPO reaction. It was also shown that the used $\mathrm{Ni} / \mathrm{La}_{2} \mathrm{O}_{3}$ catalyst recovers its initial $\mathrm{LaNiO}_{3}$ structure after reduction/oxidation cycles, which is valuable for catalyst regeneration by oxidation after the CPO reaction. Indeed, this peculiarity provides a method for redispersion of nickel on the $\mathrm{La}_{2} \mathrm{O}_{3}$ substrate.

\subsubsection{Hydrotalcite Precursors}

Other kinds of systems that have been applied as precursors are hydrotalcite type (HT) materials. Hydrotalcite can be described as $\mathrm{Mg}_{6} \mathrm{Al}_{2}(\mathrm{OH})_{16} \mathrm{CO}_{3} \cdot 4 \mathrm{H}_{2} \mathrm{O}$, and it is structured in $\mathrm{Mg}-\mathrm{Al}-\mathrm{OH}$ layers with the carbonate anions and water in the interlayer spaces. In this structure, $\mathrm{Mg}^{2+}$ and $\mathrm{Al}^{3+}$ ions can be replaced by metal cations such as $\mathrm{Ni}^{2+}$, $\mathrm{Co}^{2+}$, etc. HTs can be used as precursors of catalysts since calcined samples display high surface areas, basic properties and high dispersion of the oxide phase. 
Basile et al. [55] prepared Ni-containing silicate catalysts by starting from HT-like precursors, in which $\mathrm{Ni}^{-}$and silicate-loadings were varied. Upon calcination, this precursor yielded $\mathrm{Mg}_{2} \mathrm{SiO}_{4}, \mathrm{NiO}$ and a spinel-type $\mathrm{MgAl}_{2} \mathrm{O}_{4}$ phases. This formulation was then tested in the CPO reaction at different temperatures and feed ratios. The $8 \mathrm{wt} \% \mathrm{Ni}$ containing catalysts resulted highly active and selective under any operation condition, but catalysts with $2 \mathrm{wt} \% \mathrm{Ni}$ still were active but with inferior performance. The diffraction lines of the $8 \mathrm{wt} \% \mathrm{Ni}$ catalysts were similar to that of the fresh counterparts and the most intense line of metallic $\mathrm{Ni}^{0}$ was only observed in the most active catalysts. On the contrary, no diffraction lines of metallic $\mathrm{NiO}$ were observed probably because the small particle size and further reoxidation of the metal phase when recording diffraction patterns. Interestingly, different colors of the catalyst bed along the flow direction evidenced a reaction mechanism proceeding through the two-steps combustion-reforming mechanism.

Ni-containing silicate catalysts obtained by decomposition of hydrotalcite-like compounds were also tested in the CPO reaction. Increasing the silicate load resulted in a decrease of the specific surface area and the $\mathrm{Ni}$ dispersion. Moreover, the samples with large silicate content were deactivated by oxidation of metallic nickel particles [56]. Hydrotalcite structure also allows the introduction of promoters, such as halogens. Thus, fluorine-modified Ni$\mathrm{Mg}$-Al mixed oxides were prepared and tested in the partial oxidation of methane. The results revealed that fluorine was successfully introduced into $\mathrm{Ni}-\mathrm{Mg}$-Al mixed oxide via the high dispersion of $\mathrm{MgF}_{2}$. Such catalysts showed a high performance over POM without deactivation even after 120 $\mathrm{h}$ run at $1023 \mathrm{~K}$. This could be reasonably attributed to the promotional effect of the F- anions, which improved the homogeneous distribution of nickel and basicity of the catalyst with high resistance to coking and sintering [56]. By repeated "calcination-reconstruction" cycles, transition metals $(\mathrm{Cr}, \mathrm{Fe}, \mathrm{Co}, \mathrm{Ni}$ and $\mathrm{Cu})$ were introduced with ruthenium into layered double hydroxide structure. Preliminary calcination hydrotalcite was shown to markedly affect catalytic behaviour of the derived catalysts and especially their coking capacity. Among all the bimetallic

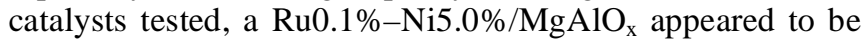
the most attractive for the dry reforming of methane because it demonstrated the highest activity and selectivity to syngas, no any induction time when generated in situ, a suitable durability and a low coking capacity [57].

\section{OTHER REFORMING TECHNOLOGIES}

\subsection{Membrane Systems}

Membrane reactors are non-porous multicomponent oxides suited to work at temperatures above $1000 \mathrm{~K}$ and have high oxygen flux and selectivity. These membranes are known as ion transport membranes (ITM). The initial design was carried out for a hydrogen refuelling station dispensing about $12.000 \mathrm{Nm}^{3} \mathrm{H}_{2}$ /day. Initial cost estimations show significant reduction in the cost of on-site high pressure $\mathrm{H}_{2}$ produced according to ITM technology in a plant of capacity in the range $3.000-30.000 \mathrm{Nm}^{3} \mathrm{H}_{2} /$ day. For instance, the cost of the $\mathrm{H}_{2}$ produced via ITM methodology appears ca. $27 \%$ cheaper than the liquid $\mathrm{H}_{2}$ transported by road.
In membrane reactors, the oxygen required to perform the CPO reaction is separated from air fed to one side of the membrane at temperatures around $300 \mathrm{~K}$ and moderate pressure (0.03-0.20 bar) and reacts on the other side with methane and steam at higher pressure (3-20 bar) to form a mixture of $\mathrm{CO}$ and $\mathrm{H}_{2}$. Then this mixture can be processed downstream to produce $\mathrm{H}_{2}$ or liquid fuels. The concept of the membrane reactor is depicted in Fig. (3). Among the different geometries employed for the ITM reactor, the flatplate system offers some advantages because it reduces the number of seals and thus makes safer operation. Among the ITM systems, perovskite structures remain prominent as they allow safe operation [58]. In the ITM oxygen is taken from air but in no case the oxygen is in direct contact with methane stream. The combination of the catalytic partial oxidation reaction and hydrogen separation in a single module results in lower operation costs. Moreover, the ITM reactor permits obtaining not only syngas mixtures but also pure hydrogen. Using the $\mathrm{La}_{1-\mathrm{x}} \mathrm{Sr}_{\mathrm{x}} \mathrm{FeO}_{3-\delta}$ perovskite series $(0$ $\leq \mathrm{x} \leq 1)$; $\mathrm{d}$ is the oxygen deficiency), it has been shown that the sample with composition $\mathrm{x}=0.3$ calcined under atmosphere at $1273 \mathrm{~K}$ produces pure hydrogen with a yield of 50\% [59]. Likewise, incorporation of small amounts of $\mathrm{NiO}$ increased both $\mathrm{CH}_{4}$ conversion and $\mathrm{H}_{2}$ selectivity, and no carbon deposit was detected.

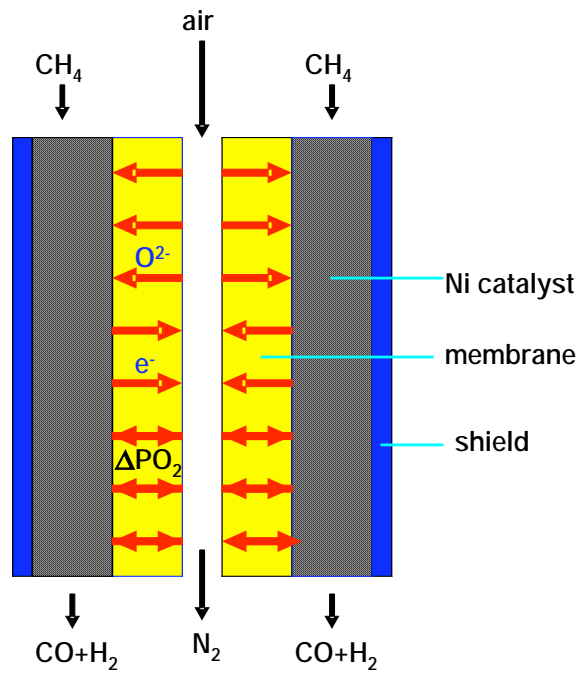

Fig. (3). Sketch diagram showing the principle of oxygen membrane reforming.

In another recent contribution, Li et al. [60] used a different perovskite system $\left(\mathrm{BaCe}_{0.1} \mathrm{Co}_{0.4} \mathrm{Fe} 0{ }_{5} \mathrm{O}_{3-\delta}\right)$ coupled to a $\mathrm{LiLaNi} / \mathrm{Al}_{2} \mathrm{O}_{3}$ catalyst. It was shown that the membrane alone was only slightly active in the CPOM reaction although incorporation of the catalyst increased both $\mathrm{CH}_{4}$ conversion and $\mathrm{CO}$ selectivity up to about $95 \%$ whereas the oxygen permeation increased by eight times higher; this performance was maintained for more than $1000 \mathrm{~h}$. A somewhat different membrane composition $\left(\mathrm{Ba}_{0.5} \mathrm{Sr}_{0.5} \mathrm{Fe}_{0.8}\right.$ $\mathrm{Zn}_{0.2} \mathrm{O}_{3-\delta}$ ) sintered at $1420 \mathrm{~K}$ was selected by Luo et al. [61] to run the CPOM reaction. For a time on-stream of $110 \mathrm{~h}$ this membrane showed $70 \% \mathrm{CH}_{4}$ conversion, $\mathrm{CO}$ selectivity above $97 \%$ and $\mathrm{a}_{2} / \mathrm{CO}$ ratio slightly above 2 . The good stability of these membranes was also confirmed by using the $\mathrm{BaCo}_{0.7} \mathrm{Fe}_{0.2} \mathrm{TaO}_{0.1} \mathrm{O}_{3-\delta}$ membrane and calcined at $1170 \mathrm{~K}$ that exhibited $99 \% \mathrm{CH}_{4}$ conversion, $94 \% \mathrm{CO}$ conversion and 
an oxygen permeation rate of $16.9 \mathrm{~mL} / \mathrm{min} . \mathrm{cm}^{2}$ for reaction time of $400 \mathrm{~h}$ at $1170 \mathrm{~K}$. Recently, a dual layer ceramic hollow fibre membrane was developed by Wu et al. [62] for the CPOM reaction. This membrane included three components: yttria-stabilized zirconia, $\mathrm{La}_{0.8} \mathrm{Sr}_{0.2} \mathrm{MnO}_{3+\delta}$ and $\mathrm{NiO}$ which were mixed together with a binder polymer. The final mixture was extruded and calcined showing excellent mechanical strength. Activity tests showed that $\mathrm{CH}_{4}$ and $\mathrm{CO}$ selectivity increase, while the $\mathrm{H}_{2} / \mathrm{CO}$ ratio follows an opposite trend due to the increased oxygen permeation rate. Although coke formation during the reaction greatly damage membrane, the activity of the inner layer can be easily recovered by periodically switching between the reaction stream and the sweep gas.

A key challenge in the development of catalytic membranes is the absolute pressure difference across the membrane. It may render the process non-economical if air must be compressed to ensure similar pressures on the two sides of the membrane. A high mechanical strength of the membrane is needed if ambient air pressure is used. In any case, the process may be best suited for small or medium scale applications. At the present stage of development of membranes it is not possible to predict when they will be ready for commercial use. Essential issues still remain to be solved, and this technology does not appear to be a competitor for large scale production of synthesis gas within the foreseeable future.

\subsection{Plasma Reforming}

The energy required to perform the partial oxidation of methane can be supplied by plasma. There are different types of electrical discharge such as dielectric barrier discharge, corona, gliding and microwave plasma. Plasmas use most of the electrical energy to form free radicals needed to start the oxidation reaction. Typical temperatures of thermal plasmas are $3.000-10.000 \mathrm{~K}$ which accelerate the kinetics of reforming reactions even in the absence of a catalyst. In methane oxidation, both methane and oxygen are introduced into the reactor and $\mathrm{H}_{2}$ plus other hydrocarbons and carbon oxides, i.e. $\mathrm{C}_{2} \mathrm{H}_{2}, \mathrm{C}_{2} \mathrm{H}_{4}, \mathrm{CO}, \mathrm{CO}_{2}$, are formed [63]. The new designs of plasma reformer are very flexible: it is possible to change the geometry of the electrodes, the reaction volume, and the inter-electrode gap. It can operate in a large range of operating conditions: auto-thermal or steam reforming conditions and allows the use of different feed stocks which is very tolerant to sulphur content and carbon deposit [64].

Several works dealing with the utilisation of plasmas for hydrogen generation by partial oxidation of methane have been published recently [65-68]. Chen et al. [65] investigated the oxidation of methane-air mixtures at ambient temperature by using a dielectric-barrier plasma assisted process. In the absence of catalyst they found that increasing the input power increases both $\mathrm{CH}_{4}$ conversion and $\mathrm{CO}_{\mathrm{x}}$ and methanol yields. The same effect was observed when changing the discharge frequency of discharge. Incorporation of a catalyst led to an increase of both $\mathrm{CH}_{4}$ conversion and methanol selectivity even working in the region of low temperatures (300-500 K). In another work, Kim and Chun [66] reported data about the arc-discharge plasma reforming of methane using a basic configuration of the experiment consisting of a fixed-bed catalyst $(\mathrm{Ni})$ bed located just below the plasma region. Almost complete $\mathrm{CH}_{4}$ conversion was obtained with $\mathrm{H}_{2}$ yield up to $94 \%$, and this was increased upon adding steam to the feed. When a high voltage (HV) is applied to a gas, the gas can be ionized due to electric energy discharge via the impact of gas molecules or atoms with electrons energized by the applied electric field, which results in the formation of plasma, the fourth state of matter in which electrons and ions coexist in the gas. If the temperature of electrons is higher than that of the gas, this kind of plasma is called non-thermal plasma (NTP), nonequilibrium plasma, or cold plasma. Reactive species (such as atoms and radicals) and lights are generated within the discharge space. Applications of plasma discharge are strongly related with the plasma produced reactive species and lights. NTP has also been investigated widely for cleanings of harmful gases, such as NOx, volatile organic compounds and PM removals, and for other applications such as methane conversion [69-76]. The important advantages of this technology for the automotive applications are: the very short time start-up (few seconds), the large operating range of fuel power (from 10 to $40 \mathrm{~kW}$ ), its compactness and robustness. The best steam reforming showed $95 \%$ conversion of $\mathrm{CH}_{4}$ and specific energy use of $14 \mathrm{MJ} / \mathrm{kg} \mathrm{H}$, equivalent to about $10 \%$ of the higher heating value of hydrogen.

\section{SMALL SCALE NATURAL GAS REFORMERS}

On-site hydrogen production is believed to be an important stepping-stone technology running in parallel with the application of fuel cells in the transport sector. This is the option to be considered in the development of hydrogen infrastructures in Japan, US and Europe where all the demonstration projects have included service stations with on-site production units. Current infrastructure development is mainly part of demonstration projects, and experiences show that hydrogen from on-site production is more competitive compared to many other alternatives. Even though the most cost-effective way of producing and transporting hydrogen is via large scale steam methane reforming and pipeline transport, the investment cost of this technology makes it prohibitive. Therefore the development of small-scale natural gas reformers for distributed hydrogen production is considered one of the most promising nearterm alternatives. A number of engineering and economic analytical studies have identified this technology as the leastcost near term technology especially at low hydrogen demand [77]. There are a number of demonstration projects involving distributed onsite production via natural gas have been installed and which are currently being tested.

There are currently a few of these demonstration onsite natural gas reformer stations operating around the world with fairly low total hydrogen production. Chevron built up two stations in Oakland (150 kg/day) and Chino (autothermal reformer producing $12 \mathrm{~kg} \mathrm{H}_{2} /$ day). Similarly, Sunline Transit operated a natural gas reformer station (Hyradix reformer $240 \mathrm{~kg} /$ day) in Thousand Palms [78]. In addition to these California demonstrations, a number of other demonstrations are occurring throughout the US and around the world in Asia and Europe [79]. These stations and other projects are supported by a number of companies which are working on improving the design and performance, and reducing production costs for these compact natural gas reformers. In 
addition, following the road map for outlined by Japanese government to supply FC powered cars, Honda and Plug Power have agreed to develop compact reformers and refueling stations which will be operative in 2015 .

For the long term, hydrogen production from natural gas has several challenges. To capture the full environmental benefits, hydrogen production for transport would likely require zero or near zero life-cycle greenhouse gas emission. Natural gas based hydrogen production can lower emissions of GHGs but without carbon capture and sequestration, it does not offer the important reductions required for the stabilisation of atmospheric $\mathrm{CO}_{2}$ levels. In addition, the supplies of natural gas are constrained in many parts of the world giving rise to prices that are high volatile. Despite these challenges, the hydrogen economy will be powered, in large part, by natural gas as it grows nowadays by the fracking methodology and attempts to transition to more sustainable form of primary energy.

\section{CONCLUSIONS}

Examination of the catalyst performance of many catalysts in the catalytic partial oxidation of methane pointed to marked differences in the reaction mechanism over transition metals. Among the differences that remain prominent are methane dissociation, binding site preferences, the stability of $\mathrm{OH}$ surface species, surface residence times of active species and contributions from lattice oxygen atoms which support species. The work carried out demonstrated that there is not a unique mechanism which can be proposed. Methane molecules dissociate on a reduced catalytic surface, but dissociation can also occur at elevated temperatures on oxides of active species which become reduced by direct interaction with methane or from the reaction with $\mathrm{H}_{2}, \mathrm{C}$ or CO. For noble metal catalysts $(\mathrm{Rh}$ and $\mathrm{Pt})$, the elementary reaction steps have shown that the production of hydrogen as a primary product depends on the high activation energy barrier to the formation of $\mathrm{OH}$. Therefore, a given metalsupport system which does not stabilize $\mathrm{OH}$ groups is desirable. Another key property of the metal-support system active in the production of $\mathrm{H}_{2}$ and $\mathrm{CO}$ as primary products is its ability to keep a low surface coverage of intermediates, such that the probability of $\mathrm{O}-\mathrm{H}, \mathrm{O}-\mathrm{CO}$ and $\mathrm{OH}-\mathrm{H}$ interactions are decreased. Reducing the energy barriers to $\mathrm{H}_{2}$ and $\mathrm{CO}$ desorption is beneficial, as would be inhibiting their re-adsorption in a subsequent part of the bed. In addition, the catalyst has to be stable towards carbon deposition and coke formation at these low surface coverages.

The large body of work developed in the field of catalytic partial oxidation of methane indicates that catalyst formulations and reaction conditions are well established. Notwithstanding there are possibilities for continued research such as precise design of the catalyst structures which result in improved stability. A critical issue is the generation of nano-sized embedded metal particles that are stabilized in a substrate, whose metal particle sizes are smaller than the ensembles typically required for carbon formation and growth. Another important area to be studied in detail is the nature and role of promoters. While several promoters have been proposed and used to increase the dispersion of nickel catalysts, optimisation of loading and ratio of catalyst and promoter is still based on trial and error. The development of theoretical models that can predict the effect of different promoters on catalyst dispersion and stability would be very valuable. There is also room for investigating the effect of alloy formation in complex systems by stabilizing and altering metal particle size and shape. The reaction of methane with lattice oxygen from oxide precursors, i.e. hydrotalcites and perovskites, can be studied in cycling experiments. The concept of cyclic operation can be extended not only to metal oxide precursors but also to supported metal catalysts where the surface residence time and concentration of oxygen is optimized for synthesis gas production. Finally, theoretical studies including DFT calculations for large clusters including kinks and steps are certainly worth investigating on all relevant transition metals.

\section{CONFLICT OF INTEREST}

The authors confirm that this article content has no conflict of interest.

\section{ACKNOWLEDGEMENTS}

Declared none.

\section{REFERENCES}

[1] Global, BP. Annual Report, 2011

[2] Pena, M.; Gomez, J.; Fierro, J.L.G. New catalytic routes for syngas and hydrogen production. Appl. Catal. A: Gen. 1996, 144, 7-57.

[3] Wender, I. Reactions of synthesis gas. Fuel Process. Technol., 1996, 48, 189-297.

[4] Rostrup-Nielsen, J.R.; Sehested, J.; Norskov, J.K. Hydrogen and synthesis gas by steam- and $\mathrm{CO}_{2}$ reforming. Adv. Catal., 2002, 47, 65-138.

[5] Collodi, G.; Wheeler, F. Hydrogen production via steam reforming with $\mathrm{CO}_{2}$ capture. Chem. Eng. Trans., 2010, 19, 37-42.

[6] Enger, B.C. ; Lødeng, R. ; Holmen, A. A review of catalytic partial oxidation of methane to synthesis gas with emphasis on reaction mechanisms over transition metal catalysts. Appl. Catal. A: Gen. 2008, 346, 1-27.

[7] Navarro, R M.; Pena, M. A.; Fierro, J.L.G. Hydrogen Production Reactions from Carbon Feedstocks: Fossil Fuels and Biomass. Chem. Rev. 2007, 107, 3952-3991.

[8] York, A.P.E.; Xiao, T.; Green, M.L.H. Brief overview of the partial oxidation of methane to. synthesis gas. Top. Catal. 2003, 22, 345358 .

[9] Mitri, A.; Neumann, D. ; Liu, T. ; G. Veser, Reverse-flow reactor operation and catalyst deactivation during high-temperature catalytic partial oxidation. Chem. Eng. Sci. 2004, 59, 5527-5534.

[10] Kolios, G.; Frauhammer, J. ; Eigenberger, G. Autothermal fixedbed reactor concepts. Chem. Eng. Sci. 2000, 55, 5945-5967.

[11] D.; Neumann, G. Veser, Catalytic partial oxidation of methane in a reverse-flow reactor. AICHE J. 2005, 51, 210-223.

[12] Biesheuvel, P.M.; Kramer, G.J. Two-section reactor model for autothermal reforming of methane to synthesis gas, AICHE J. 2003 , 49. 1827-1837.

[13] Schicks, J.; Neumann, D.; Specht, U.; Veser, G. Nanoengineered catalysts for high-temperature methane partial oxidation. Catal. Today 2003, 81, 287-296.

[14] Basini, G.; Aasberg-Petersen, K.; Guarinoni, A.; Oestberg, M. Catalytic partial oxidation of natural gas at elevated pressure and low residence time. Catal. Today 2001, 64, 9-20.

[15] Hickman, D.A. ; Schmidt, L.D. Production of syngas by direct catalytic oxidation of methane. Science, 1993, 259(5093),343-6.

[16] Torniainen, P.M. ; Chu, X. ; Schmidt, L.D. Comparison of monolith-supported metals for the direct oxidation of methane to syngas. J. Catal. 1994, 146, 1-10.

[17] Dietz III, A.G. ; Schmidt, L.D. Partial oxidation of methane to synthesis gas over $\mathrm{Rh} / \alpha-\mathrm{Al}_{2} \mathrm{O}_{3}$ at high temperatures, Catal. Lett., 1995, 33, 15-29. 
[18] Lanza, R.; Velasco, J.A.; Järås, S.G. Recent developments and achievements in oxidation of methane with and without addition of steam. Catalysis 2011, 23, 50-95.

[19] Silva, F.D.; Ruiz, J.A.C. ; de Sousa, K.R. ; Bueno, J.M.C.; Mattos, L.V.; Noronha, F.B.; Hori, C.E. Partial oxidation of methane on Pt catalysts: Effect of the presence of ceria-zirconia mixed oxide and of metal content. Appl. Catal. A: Gen. 2009, 364, 122-129.

[20] Eriksson, S.; Nylén, U.; Rojas, S.; Boutonnet, M. Preparation of catalysts from microemulsions and their applications in heterogeneous catalysis, Appl. Catal. A: Gen. 2004, 265, 207-219.

[21] Zhu, Q. ; Zhao, X. ; Deng, Y. Advances in the partial oxidation of methane to synthesis gas. J. Nat. Gas Chem. 2004, 13, 191-203.

[22] Horn, R. ; Williams, K.A. ; Degenstein, N.J. ; Schmidt, L.D. Syngas by catalytic partial oxidation of methane on rhodium: Mechanistic conclusions from spatially resolved measurements and numerical simulations. J. Catal. 2006, 242, 92-102.

[23] Horn, R.; Williams, K.A.; Degenstein, N.J. ; Schmidt, L.D. Effect of $\mathrm{Rh}$ loading on the performance of $\mathrm{Rh} / \mathrm{Al}_{2} \mathrm{O}_{3}$ for methane partial oxidation to synthesis gas. Chem. Eng. Sci. 2007, 62, 1298-1307.

[24] Li, J.M. ; Huang, F.Y. ; Weng, W.Z. ; Pei, X.Q. ; Luo, C.R. ; Lin, H.Q. ; Huang, C.J. ; Wan, H.L. Effect of Rh loading on the performance of $\mathrm{Rh} / \mathrm{Al}_{2} \mathrm{O}_{3}$ for methane partial oxidation to synthesis gas. Catal. Today 2008, 131, 179-187.

[25] Beretta, A.; Groppi, G.; Lualdi, M.; Tavazzi, I.; Forzatti, P. Experimental and modeling analysis of methane partial oxidation: Transient and steady-state behavior of Rh-coated honeycomb monoliths. Ind. Eng. Chem. Res. 2009, 48, 3825-3836.

[26] Donazzi, A.; Maestri, M.; Michael, B.C.; Beretta, A.; Groppi, P.; Tronconi, E.; Schmidt, L.D.; Vlachos, D.G. Microkinetic modeling of spatially resolved autothermal $\mathrm{CH}_{4}$ catalytic partial oxidation experiments over Rh-coated foams. J. Catal. 2010, 275, 270-279.

[27] Salazar-Villalpando, M.D.; Berry, D.A.; Cugini, A. Role of lattice oxygen in the partial oxidation of methane over Rh/zirconia-doped ceria. Isotopic studies. Int. J. Hydrogen Energy 2008, 35, 19982003.

[28] Salazar-Villalpando, M.D. ; Miller, A.C. Hydrogen production by methane decomposition and catalytic partial oxidation of methane over $\mathrm{Pt} / \mathrm{Ce}_{x} \mathrm{Gd}_{1-x} \mathrm{O}_{2}$ and $\mathrm{Pt} / \mathrm{Ce}_{x} \mathrm{Zr}_{1-x} \mathrm{O}_{2}$. Chem. Eng. J. 2011, 166, 738-743.

[29] Shamsi, A. Partial oxidation of methane and the effect of sulfur on catalytic activity and selectivity. Catal. Today, 2009, 139, 268-273.

[30] Lanza, R.; Järås, S.G.; Canu, P. Microemulsion-prepared ruthenium catalyst for syngas production via methane partial oxidation. Appl. Catal. A: Gen. 2008, 337, 10-18.

[31] Lanza, R. ; Järås, S.G. ; Canu, P. Partial oxidation of methane over $\mathrm{Pt}-\mathrm{Ru}$ bimetallic catalyst for syngas production. Appl. Catal. A: Gen. 2008, 348, 221-228.

[32] Choque, V. ; de la Piscina, P.R. ; Molyneux, D. ; Homs, N. Ruthenium supported on new $\mathrm{TiO}_{2}-\mathrm{ZrO}_{2}$ systems as catalysts for the partial oxidation of methane. Catal. Today 2010, 149, 248-253.

[33] Wang, M.; Weng, W.; Zheng, H.; Yi, X.; Huang, C.; Wan, H. Oscillations during partial oxidation of methane to synthesis gas over $\mathrm{Ru} / \mathrm{Al}_{2} \mathrm{O}_{3}$ catalyst. J. Nat. Gas Chem, 2009, 18, 300-305.

[34] Ryu, J.H. ; Lee, K.Y. ; Kim, H. J. ; Yang, J. I. ; Jung, H. Promotion of palladium-based catalysts on metal monolith for partial oxidation of methane to syngas. Appl. Catal. B: Environ. 2008, 80, 306-312.

[35] Burgess, L. Wealth Daily, May $21^{\text {st }}, \mathbf{2 0 1 0}$

[36] Ruckenstein, E. ; Hu, Y.H. Role of support in $\mathrm{CO}_{2}$ reforming of $\mathrm{CH}_{4}$ to syngas over Ni catalysts. J. Catal., 1996, 162, 230-238.

[37] Tsipouriari, V.A.; Zhang, Z.; Verykios, X.E. Catalytic Partial Oxidation of Methane to Synthesis Gas over Ni-Based Catalysts: I. Catalyst Performance Characteristics. J. Catal., 1998, 179, 283291.

[38] Barbero, J.; Peña, M.A.; Campos-Martín, J. M.; Fierro, J.L.G.; Arias, P.L. Support effect in supported Ni catalysts on their performance for methane partial oxidation. Catal. Lett., 2003, 87, 211-218.

[39] Hu, Y.H.; Ruckenstein, E. Binary MgO-based solid solution catalysts for methane conversion to syngas. Catal. Rev.-Sci. Eng., 2002, 44, 423-453.

[40] Requies, J.; Cabrero, M.A.; Barrio, V.L.; Guemez, M. B.; Cambra, J. F.; Arias, P.L.; Perez-Alonso, F.J.; Ojeda, M.; Pena, M.A.; Fierro, J.L.G. Partial oxidation of methane to syngas over Ni/MgO and $\mathrm{Ni} / \mathrm{La}_{2} \mathrm{O}_{3}$ catalysts. Appl. Catal. A: Gen., 2005, 289, 214-223.
[41] Bitter, J.H.; Hally, W.; Seshan, K.; van Ommen, J. G.; Lercher, J.A. The role of the oxidic support on the deactivation of $\mathrm{Pt}$ catalysts during the $\mathrm{CO}_{2}$ reforming of methane. Catal. Today, 1996, 29, 349-353.

[42] Passos, F. B. ; de Oliveira, E. R. ; Mattos, L.V. ; Noronha, F.B. Partial oxidation of methane to synthesis gas on $\mathrm{Pt} / \mathrm{Ce}_{x} \mathrm{Zr}_{1-x} \mathrm{O}_{2}$ catalysts: the effect of the support reducibility and of the metal dispersion on the stability of the catalysts. Catal. Today, 2005, 101, 23-30.

[43] Passos, F. B. ; de Oliveira, E. R. ; Mattos, L.V. ; Noronha, F.B.Effect of the support on the mechanism of partial oxidation of methane on platinum catalysts, Catal. Lett. 2006, 110, 161-167.

[44] M.D. Salazar-Villalpando, D.A. Berry, T.H. Gardner, Partial oxidation of methane over Rh/supported-ceria catalysts: Effect of catalyst reducibility and redox cycles. Int. J. Hydrogen Energy, 2008, 33, 2695-2073.

[45] Chang, J.S. ; Park, S.E. ; Yoo, J.W. ; Park, J.N. Catalytic behavior of supported $\mathrm{KNiCa}$ catalyst and mechanistic consideration for carbon dioxide reforming of methane. J. Catal., 2000, 195, 1-11.

[46] Jing, Q.S.; Zheng, X.M. Combined catalytic partial oxidation and $\mathrm{CO}_{2}$ reforming of methane over $\mathrm{ZrO}_{2}$-modified $\mathrm{Ni} / \mathrm{SiO}_{2}$ catalysts using fluidized-bed reactor Energy, 2006, 31, 2184-2192.

[47] Araujo, J.C.S.; Zanchet, D.; Rinaldi, R.; Schuchardt, U.; Hori, C.E.; Fierro, J.L.G.; Bueno, J.M.C. The effects of $\mathrm{La}_{2} \mathrm{O}_{3}$ on the structural properties of $\mathrm{La}_{2} \mathrm{O}_{3}-\mathrm{Al}_{2} \mathrm{O}_{3}$ prepared by the sol-gel method and on the catalytic performance of $\mathrm{Pt} / \mathrm{La}_{2} \mathrm{O}_{3}-\mathrm{Al}_{2} \mathrm{O}_{3}$ towards steam reforming and partial oxidation of methane. Appl. Catal. B: Environ. 2008, 84, 552-562.

[48] Eriksson, S. ; Rojas, S. ; Boutonnet, M. ; Fierro, J.L.G. Effect of Ce-doping on $\mathrm{Rh} / \mathrm{ZrO}_{2}$ catalysts for partial oxidation of methane. Appl. Catal. A: Gen., 2007, 326, 8-16.

[49] Larrondo, S. A.; Kodjaian, A.; Fabregas, I.; Zimicz, M. G.; Lamas, D.G.; Walsoe de Reca, B.E.; Amadeo, N.E. Methane partial oxidation using $\mathrm{Ni} / \mathrm{Ce}_{0.9} \mathrm{Zr}_{0.1} \mathrm{O}_{2}$ catalysts. Int. J. Hydrogen Energy 2008, 33, 3607-3613.

[50] Silva, F.A.; Martinez, D.S.; C Ruiz, J.A.; Mattos, L.V.; Hori, C.E.; Noronha, F.B. The effect of the use of cerium-doped alumina on the performance of $\mathrm{Pt} / \mathrm{CeO}_{2} / \mathrm{Al}_{2} \mathrm{O}_{3}$ and $\mathrm{Pt} / \mathrm{CeZrO} \mathrm{Zr}_{2} / \mathrm{Al}_{2} \mathrm{O}_{3}$ catalysts on the partial oxidation of methane. Appl. Catal. A. Gen. 2008, 335, $145-152$.

[51] Lago, R. ; Bini, G.; Peña, M.A.; Fierro, J.L.G. Partial Oxidation of Methane to Synthesis Gas Using $\mathrm{LnCoO}_{3}$ Perovskites as Catalyst Precursors, J. Catal., 1997, 167, 198-209.

[52] Daí, X.; Yu, C. Direct partial oxidation of methane to synthesis gas using oxygen carriers in the absence of gaseous oxygen, Prog. Chem. 2009, 21, 1626-1635.

[53] Shishido, T.; Sukenobu, M.; Morioka, H.; Kondo, M.; Wang, Y.; Takaki, K.; Takehira, K. Partial oxidation of methane over Ni/MgAl oxide catalysts prepared by solid phase crystallization method from $\mathrm{Mg}-\mathrm{Al}$ hydrotalcite-like precursors. Appl. Catal. A: Gen. 2002, 223, 35-42.

[54] Pereniguez, R.; Gonzalez-de la Cruz, V.M.; Holgado, J.P.; Caballero, A. Synthesis and characterization of a $\mathrm{LaNiO}_{3}$ perovskite as precursor for methane reforming reactions catalysts. Appl. Catal. B: Environ. 2010, 93, 346-353.

[55] Basile, F.; Benito, P.; Fornasari, G.; Gazzoli, D.; Pettiti, I.; Rosetti, V.; Vaccari, A. Ni-catalysts obtained from silicate intercalated HTlcs active in the catalytic partial oxidation of methane: Influence of the silicate content. Catal. Today, 2009, 142, 78-84.

[56] Zhang, J. ; Wei, W. ; Sun, Y. Fluroine-modified mesoporous Ni$\mathrm{Mg}-\mathrm{Al}$ mixed oxides for partial oxidation methane. Catal. Lett., 2010, 135, 321-329.

[57] Tsyganok, A.I.; Inaba, M.; Tsunoda, T.; Uchida, K.; Suzuki, K.; Takehira, K.; Hayakawa, T. Rational design of Mg-Al mixed oxide-supported bimetallic catalysts for dry reforming of methane. Appl. Catal. A: Gen., 2005, 292, 328-343.

[58] Sanders, M.; O'Hayre, R. Development of a multispecies transport space theory and its application to permeation behavior in proton-conducting doped perovskites. J. Mater. Chem. 2010, 20, 6271-6281.

[59] Evdou, A.; Nalbandian, L.; Zaspalis, V.T. Perovskite membrane reactor for continuous and isothermal redox hydrogen production from the dissociation of water. J. Memb. Sci., 2008, 325, 704-711.

[60] García-García, F. R.; Rahman, M. A.; Kingsbury, B. F.K.; Li, K. Asymmetric ceramic hollow fibres: New micro-supports for gasphase catalytic reactions. Appl. Catal. A: Gen. 2011, 393, 71-77. 
[61] Luo, H.; Jiang, H. ; Klande, T.; Cao, Z.; Liang, F.; Wang, H.; Caro, J. Novel Cobalt-Free, Noble Metal-Free Oxygen-Permeable $40 \mathrm{Pr}_{0.6} \mathrm{Sr}_{0.4} \mathrm{FeO}_{3-\delta}-60 \mathrm{Ce}_{0.9} \mathrm{Pr}_{0.1} \mathrm{O}_{2-\delta}$ Dual-Phase Membrane. Chem. Mater.2012, 24, 2148-2154.

[62] Wu, Z.; Wang, B.; Li, K. Functional LSM-ScSZ/NiO-ScSZ duallayer hollow fibres for partial oxidation of methane. Int. $J$. Hydrogen Energy, 2011, 36, 5334-5341.

[63] Sekiguchi, H.; Mori, Y. Steam plasma reforming using microwave discharge. Thin Solid Films, 2003, 435, 44-48.

[64] Paulmier, T.; Fulcheri, L. Use of non-thermal plasma for hydrocarbon reforming. Chem. Eng. J., 2005, 106, 59-71.

[65] Chen, L.; Zhang, X.W.; Huang, L.; Lei, L.C. Partial oxidation of methane with air for methanol production in a post-plasma catalytic system. Chem. Eng. Process., 2009, 48, 1333-1340.

[66] Kim, S.C.; Chun, Y.N. Production of hydrogen by partial oxidation with thermal plasma, Renew. Energy 2008, 33, 1564-1569.

[67] Pushkraev, A. I.; Zhu, A. M. ; Li, X. S.; Sazonov, E.V. Mehane conversion in low-temperature plasma. High Energy Chem. ,2009, 43, 156-162.

[68] Luche, J.; Aubry, O.; Kacef, A.; Cormier, J.M. Syngas production from methane oxidation using a non-thermal plasma: Experiments and kinetic modeling. Chem. Eng. J. , 2009, 149, 35-41.

[69] Yao, S.; Ouyang, F.; Nakayama, A.; Suzuki, E.; Okumoto, M.; Mizuno, A. Oxidative coupling and reforming of methane with carbon dioxide using a high frequency pulsed plasma. Energy Fuels, 2000, 14, 910-914.

[70] Yao, S.; Nakayama, A.; Suzuki, E. Methane conversion using a high-frequency pulsed plasma: discharge features. AIChE J., 2001, $47,419-426$.
[71] Yao, S.; Nakayama, A.; Suzuki, E. Methane conversion using a high-frequency pulsed plasma: important factors. AIChE J., 2001, 47, 413-418.

[72] Yao, S.; Okumoto, A.; Nakayama, A.; Suzuki, E. Plasma reforming and coupling of methane with carbon dioxide. Energy Fuels, 2001, 15, 1295-1299.

[73] Yao, S.; Suzuki, E.; Meng, N.; Nakayama, A. Influence of rise time of pulse voltage on the pulsed plasma conversion of methane. Energy Fuels, 2001, 15, 1300-1303.

[74] Yao, S.; Nakayama, A.; Suzuki, E. Acetylene and hydrogen from pulsed plasma conversion of methane. Catal. Today, 2001, 71, 219223.

[75] Yao, S.; Suzuki, E. ; Meng, N.; Nakayama, A., A high-efficiency reactor for the pulsed plasma conversion of methane. Plasma Chem. Plasma Process, 2002, 22, 225-237.

[76] Yao, S.; Takemoto, T.; Ouyang, F.; Nakayama, A.; Suzuki, E.; Mizuno, A.; Okumoto, M. Selective oxidation of methane using a non-thermal pulsed plasma. Energy Fuels, 2000, 14, 459-463.

[77] Yang, C.; Ogden, J.M. Urban hydrogen infrastructure costs using the steady state city hydrogen infrastructure system model (SSCHISM). In: National Hydrogen Association Annual Meeting, 2007, San Antonio, TX.

[78] Yang, C.; Ogden, J. Advanced Energy Pathways (AEP) Project, UC Davis, Institute of Transportation Studies, 2007.

[79] Worldwide $\mathrm{H}_{2}$ Refueling Stations, 2007, Fuel Cells 2000. Available at: www.fuelcells.org .

(C) Saleh A. Al-Sayari; Licensee Bentham Open.

This is an open access article licensed under the terms of the Creative Commons Attribution Non-Commercial License (http://creativecommons.org/licenses/by-nc/ 3.0/) which permits unrestricted, non-commercial use, distribution and reproduction in any medium, provided the work is properly cited. 